\title{
THE PHOTOREDUCTION OF AROMATIC SYSTEMS
}

\author{
J. A. BARLtrop \\ Dyson Perrins Laboratory, Oxford University, Oxford, UK
}

\begin{abstract}
The irradiation of several aromatic systems (carbocyclic and heterocyclic) in the presence of aliphatic tertiary amines or sodium borohydride leads to the production of dihydro-derivatives. Three different mechanisms for photoreduction have been identified through the use of deuterated species. A system of nomenclature is proposed for categorizing various organic reduction mechanisms.
\end{abstract}

\section{INTRODUCTION}

Although hydrogen-abstraction by (and therefore reduction of) the excited carbonyl group is a well-documented reaction ${ }^{1}$, little is known about the photoreduction of other systems and almost total ignorance surrounds the photoreduction of aromatics. The Birch reduction using sodium/liquid ammonia is a thermal reaction of considerable synthetic utility and we speculated that reduction of excited aromatics might lead to products different from those obtained in the ground state, and that such photoreductions might usefully supplement the Birch reduction in certain cases. The purpose of this lecture is to report our preliminary findings in this area. It transpires that, depending on the nature of the substrate and of the reducing agent, either zero, one or two hydrogens may be transferred from the reducing agent and in order to simplify the subsequent discussion, we propose that such processes be designated types $R_{0}, R_{1}$ and $R_{2}$ reductions ( $R$ implying reduction and the numerical subscript the number of hydrogens transferred from the reducing agent). Of course, a given number of hydrogens may be transferred in different ways. For example, a Type $R_{1}$ reaction could, in principle, proceed by the addition of either (a) $\mathrm{H}^{-}$, then $\mathrm{H}^{+}$(from the solvent) or (b) $\mathrm{H}^{+}$and then $\mathrm{H}^{-}$. We therefore propose that where necessary, the initial entity transferred to the substrate (be it from solvent or reducing agent) should also be specified.

Thus cases (a) and (b) could be designated $\mathrm{R}_{1} \mathrm{H}^{-}$and $\mathrm{R}_{1} \mathrm{H}^{+}$respectively. Similarly, initial electron transfer could be signified by the suffix $E$, e.g. $R_{0} E$. The utility of the system will, I hope, become clear as we proceed.

Our interest in this area was stimulated by contemplating the results of the masterly researches of Weller and his co-workers on the interaction between excited aromatic hydrocarbons and aromatic amines. They found ${ }^{2}$ that when 


\section{J. A. BARLTROP}

increasing amounts of, say, diethylaniline were added to anthracene in nonpolar solvents, the fluorescent emission of the hydrocarbon diminished in intensity with the concomitant appearance of a new broad structureless emission at longer wavelength which was shown to be due to the formation of an exciplex (i.e. a complex between the excited hydrocarbon and the aromatic amine). Similar phenomena have since been observed with aromatic hydrocarbons and other electron donors. A simple MO treatment due to Weller is as follows:
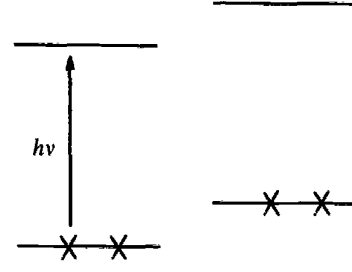

$\mathrm{A}+\mathrm{D}$

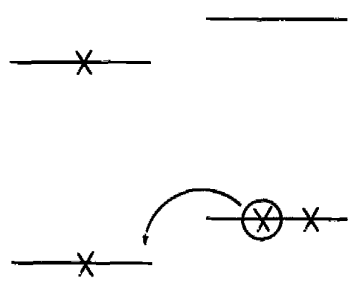

$A^{\star}+\mathrm{D}$
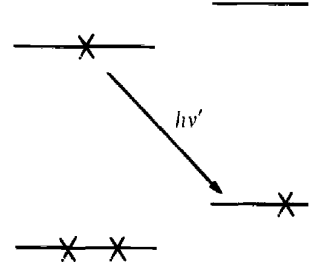

$\left(\mathrm{A}^{-} \cdot \mathrm{D}^{+}\right)$

Exciplex

(Acceptor) (Donor)

This accounts for the highly polar character of exciplexes ( $\sim 10$ Debyes) and for the fact that $\lambda_{\max }$ for exciplex emission depends upon the ionization potential of the donor and the electron affinity of the acceptor. The model is tantamount to writing the wave function of the exciplex as

$$
\psi_{(\mathrm{AD}) \star}=a \psi_{\mathrm{A}-\mathrm{D}+}+b \psi_{\mathrm{A}+\mathrm{D}-}+c \psi_{\mathrm{A}^{\star} \mathrm{D}}+d \psi_{\mathrm{AD}^{\star}}
$$

and neglecting all terms except the first.

The intensity of exciplex emission diminishes with increase in solvent polarity, becoming zero in highly polar solvents like acetonitrile. In such solvents, the addition of amines is observed merely to cause quenching of the fluorescence of the hydrocarbon. Flash-photolysis of strongly quenched solutions in acetonitrile gave rise to radical ions showing that in such solutions complete transfer of an electron occurs between the donor and acceptor. One can think of this as dissociation of the exciplex and solvation of its components or in terms of direct electron-transfer between donor and aromatic

$$
(A D)^{\star} \rightarrow A_{s}^{-}+D_{s}^{+}
$$

hydrocarbon without the intervention of an exciplex, the transfer occurring in an encounter/collision complex. Thus:

$A^{\star}+D$

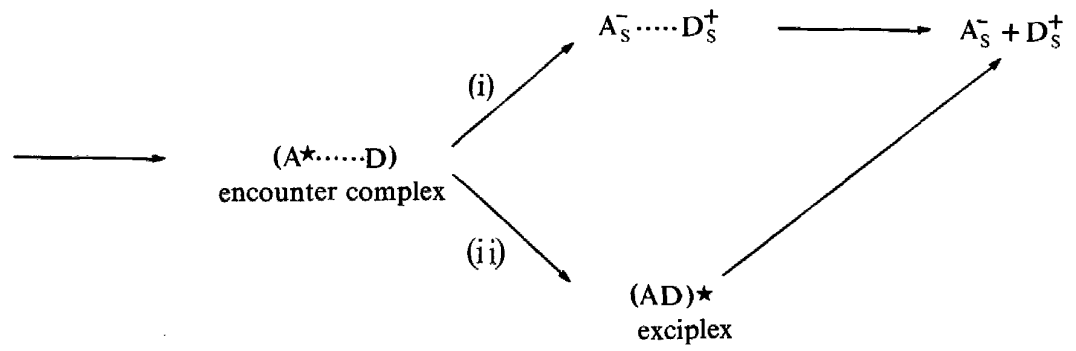


Since a kinetic analysis ${ }^{3}$ of the implications of path (i) adequately explains the extensive quenching data obtained in polar solvents it seems that path (ii) can be only a minor one. Path (i) may also be the dominant one in non-polar solvents in which exciplexes are known to be present through their fluorescence.

The formation of the radical-ion of the aromatic hydrocarbon implies reduction and such an entity in a protic solvent would be expected to be protonated extremely rapidly to give a radical corresponding to a reduced hydrocarbon, which, on further reduction or dismutation would give a dihydromatic.

$$
\mathrm{Ar}^{\circ}+\mathrm{H}^{+} \longrightarrow \mathrm{ArH}^{*}[\underbrace{\mathrm{cog}}_{\mathrm{H}}
$$

Furthermore, this radical would be generated in the immediate environment of the amine radical cation formed simultaneously so that bonding might be expected to ensue between the two components of the system.

With this in mind, we decided to irradiate various aromatic systems in the presence of aliphatic, rather than aromatic amines to ensure that only the aromatic hydrocarbon was excited. It had already been shown ${ }^{4}$ that exciplexes are formed in such systems.

Subsequently, and in the light of experience gained from our work using aliphatic amines, we examined the photochemical reduction of aromatics by sodium borohydride. This lecture is concerned with both these topics.

\section{PHOTOREDUCTION OF AROMATICS BY ALIPHATIC AMINES}

When naphthalene was irradiated with excess triethylamine in two per cent aqueous acetonitrile with a medium pressure mercury arc, through quartz, the naphthalene rapidly disappeared and was replaced by a number of products, separated into neutral and basic fractions, the components of which were isolated by liquid chromatography. The compounds were identified $^{5}$ as:<smiles>C1=CCc2ccccc2C1</smiles><smiles>c1ccc2c(c1)CCCC2</smiles><smiles>CCN(CC)C1C=CCc2ccccc21</smiles>

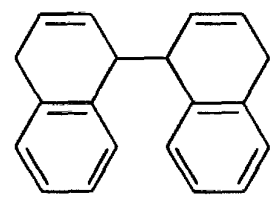

A corresponding irradiation of 1-methoxynaphthalene gave the following substances in which reduction had occurred in the unsubstituted ring, together with an amine fraction which was not investigated further:<smiles>COc1cccc2c1CC=CC2</smiles>

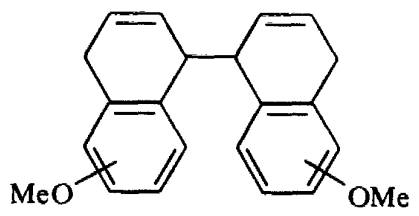




\section{J. A. BARLTROP}

With 2-methoxynaphthalene there were obtained<smiles>COC1=CCc2ccccc2C1</smiles><smiles>COC1=Cc2ccccc2CC1</smiles><smiles>COc1ccc2c(c1)CC=CC2</smiles>

and basic products. Other aromatics when subjected to this procedure give rise to the products in Table 1. It is immediately apparent:

(i) that the irradiations generated monomeric reduction products identical with those obtained by Birch reduction ${ }^{6}$,

(ii) that additional dimeric reduction products are formed which are not observed in the Birch reduction,

(iii) that reduction is, in general, accompanied by the formation of amine adducts, in which the $\alpha$-carbon atom of the amine is linked to the hydrocarbon moiety.

We seek an interpretation of these facts. We note the identity of the monomeric reduction products with those of the Birch reduction which appears to proceed by sequential transfer of electrons and protons:

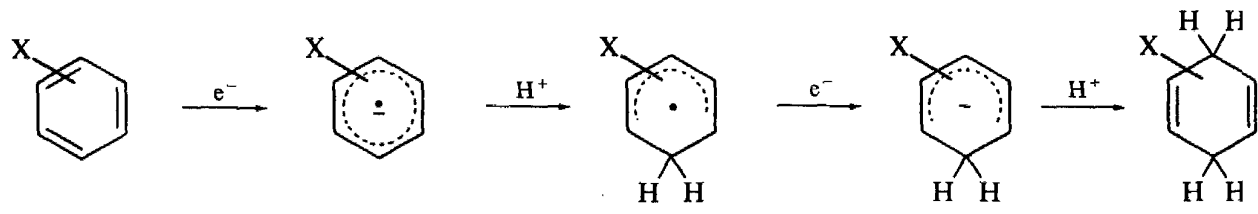

Bearing in mind that the quenching of the fluorescence of aromatic hydrocarbons by aromatic amines and other donors seems to involve more or less complete transfer of an electron to the aromatic hydrocarbon, one postulates that the initial process is

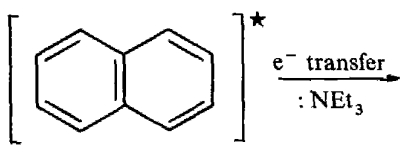

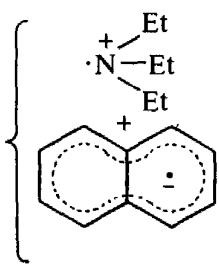

(I)

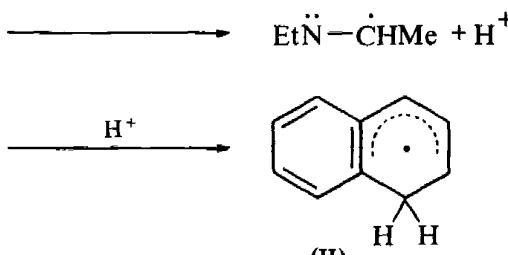

(II)

On the Weller exciplex model, the radical anion (I) is in its ground state, so that the non-adiabatic transition between the excited and ground state potential surfaces presumably occurs at this point and the rest of the transformations are thermal. Rapid protonation by the aqueous solvent now gives the radical (II), the same intermediate as is formed in a Birch reduction.

A problem now arises. In the Birch reduction, electrons are readily available in the medium and the radical (II) acquires another electron and a proton and gives rise to the dihydro-compound. In the photochemical system, electrons are not readily available. How then is the reduction completed? There can be only two possibilities-electron transfer and hydrogen atom transfer and these may be distinguished by isotope experiments. If the irradiation is conducted in $\mathrm{MeCN} / \mathrm{D}_{2} \mathrm{O}$, then the initially formed radical (III) 
will have one deuterium incorporated:

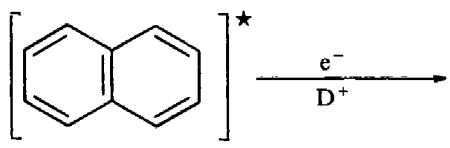

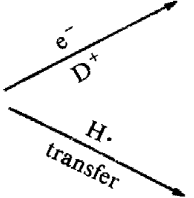

H D<smiles>[2H]C1C=CC([2H])C([2H])c2ccccc21</smiles>

(IV)

A second electron transfer will lead to a dihydronaphthalene with two deuteriums located in the 1- and 4-positions (IV). Hydrogen atom transfer leads to (V) with only one deuterium in the final product. Experiments show that the product contains $1.6 \mathrm{D}$, a number that is non-integral and greater than one.

The only way in which one can explain the incorporation of more than $1 \mathrm{D}$ in the dihydronaphthalene is to postulate (i) two or more simultaneous paths for the reduction of the deuterated radical (III), one of which incorporates an extra $1 \mathrm{D}$ and the other(s) introducing $0 \mathrm{D}$; (ii) dismutation of the radical (III). This last hypothesis may be discarded because such dismutation must lead to recovered naphthalene labelled with deuterium:<smiles>[2H]C1C=CCCCCCCCCC1</smiles>

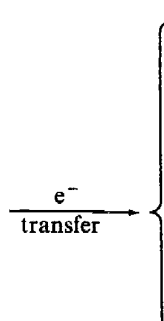

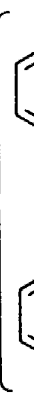<smiles></smiles>

$-\mathrm{H}^{+}$<smiles>[2H]C1C=C[CH]C(C)=C1C</smiles><smiles>[2H]C1C=C[CH]C(C)=C1C</smiles>

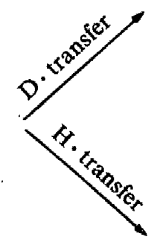<smiles>[2H]C1C=CC([2H])C([2H])c2ccccc21</smiles>

$+$<smiles>c1ccc2ccccc2c1</smiles><smiles>[2H]c1cccc2ccccc12</smiles> 


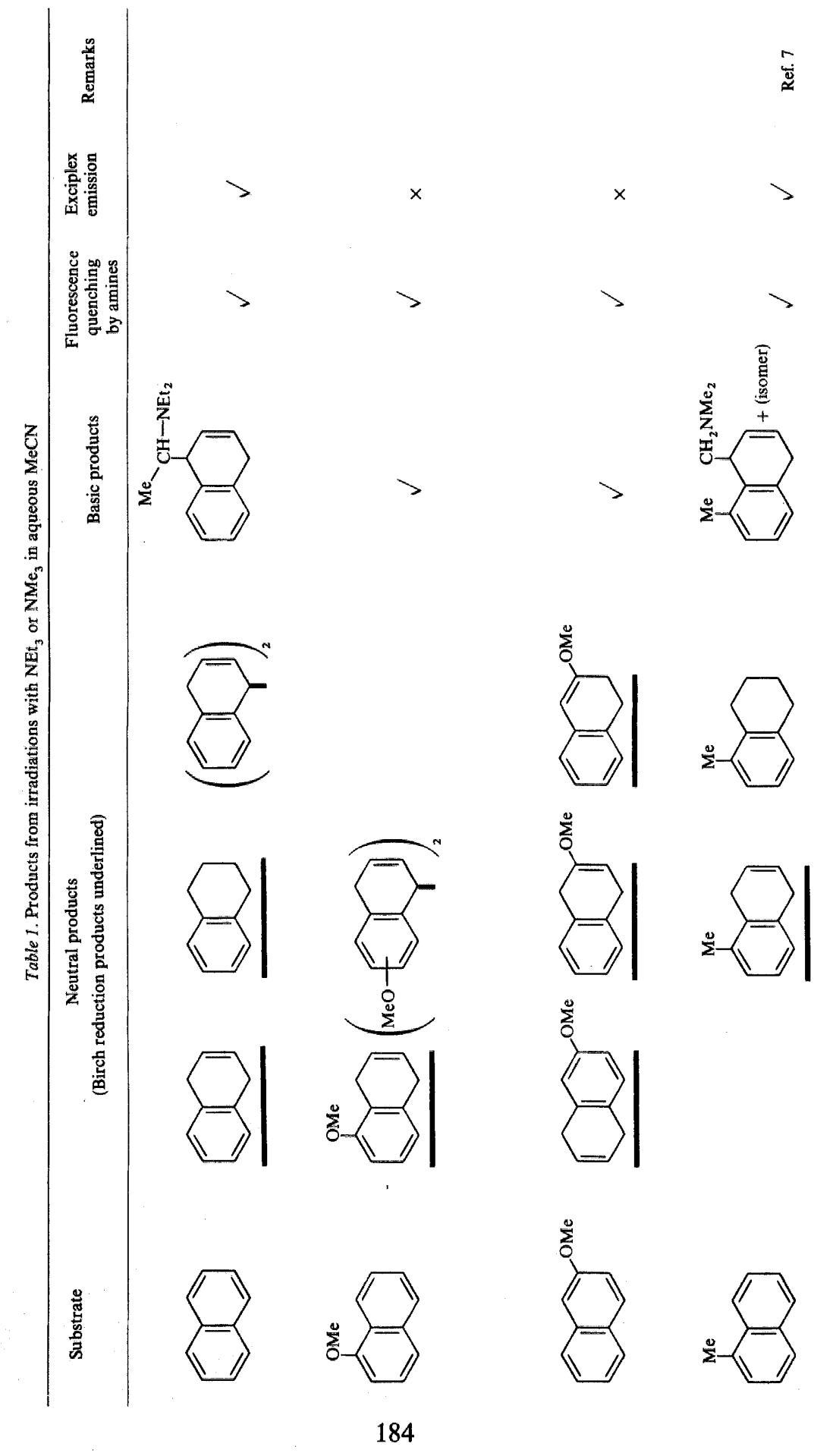




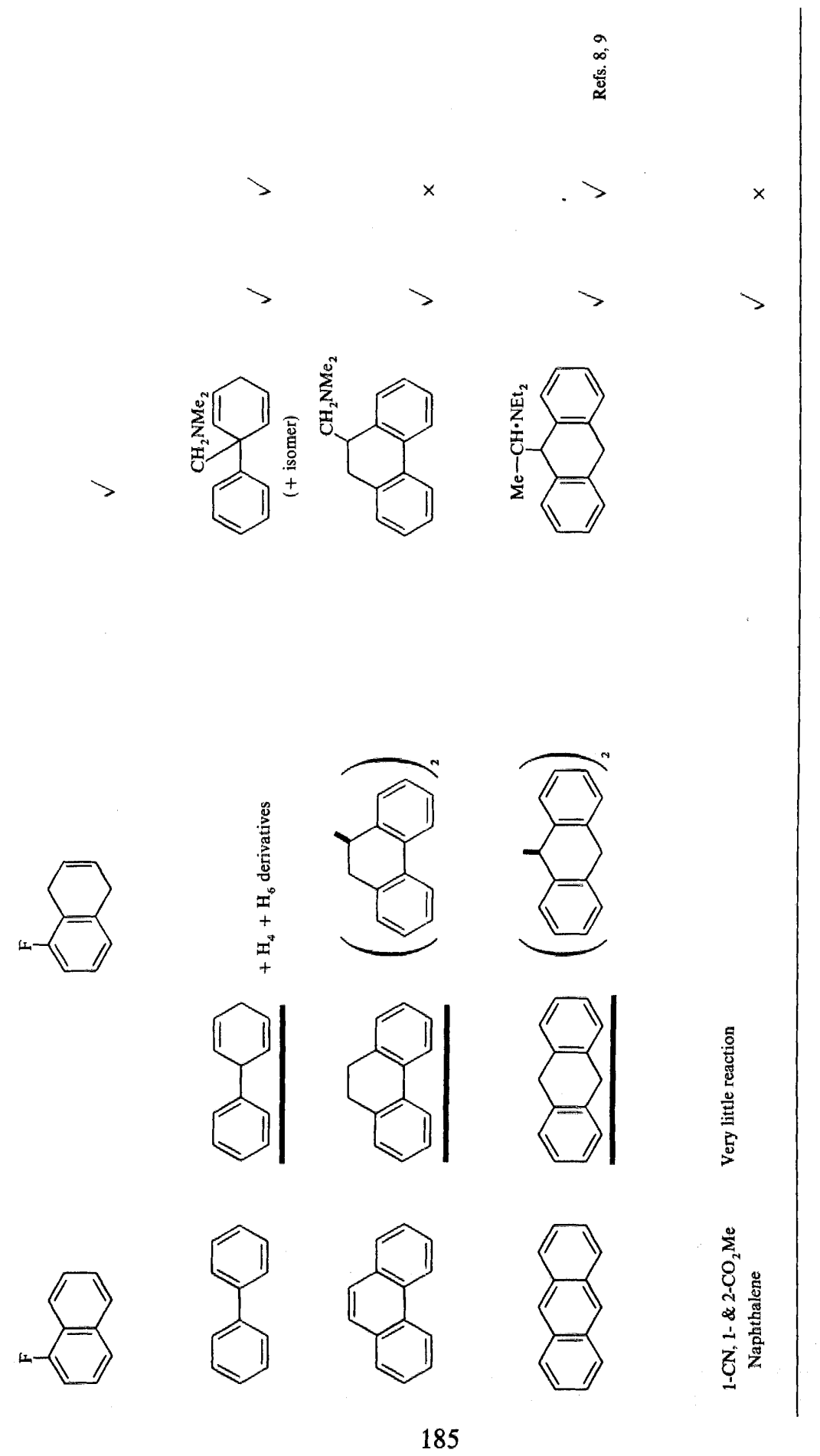




\section{J. A. BARLTROP}

No deuterium could be detected in the recovered naphthalene even in reactions conducted to 70 per cent conversion.

We are therefore left with the hypothesis of two parallel paths for the reduction of the deuterated radical (III), one proceeding by electron transfer and giving a dideuterated product and the other involving $\mathrm{H}$ atom transfer. Where this hydrogen atom originates, we cannot say, but it seems unlikely to be derived from the solvent or impurities therein, since excited benzophenone is not reduced in the solvent. Presumably, this hydrogen atom is derived from the amine (Type $R_{1} E$ ) or from some unknown phototransformation product of the naphthalene (Type $R_{0} E$ ). However this may be, there can be little doubt that the photoreduction of naphthalene to a doubly deuterated produot is initiated by electron transfer from the amine and the process therefore belongs to Type $\mathrm{R}_{0} \mathrm{E}$. The basic products presumably arise thus:
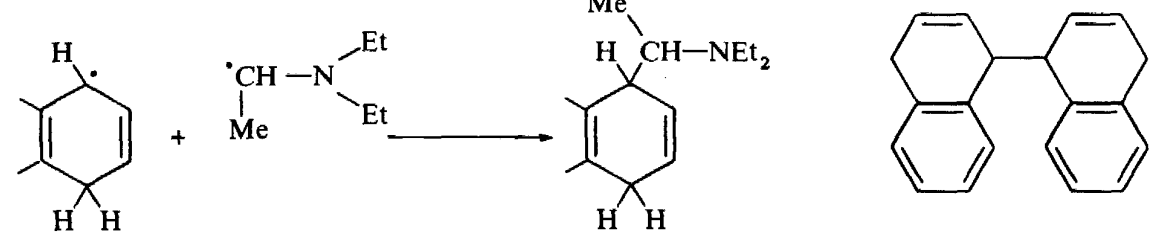

The formation of reduced dimers, e.g. (VI), provides further evidence for the intervention of the radicals (II). That such dimers are not seen in the Birch reduction presumably reflects the greater electron availability in solutions of sodium in liquid ammonia leading to further reduction of the radical before it has a chance to dimerize.

Drawing the threads together, the overall scheme for the formation of products from the system naphthalene/triethylamine/ $h v$ seems to be:

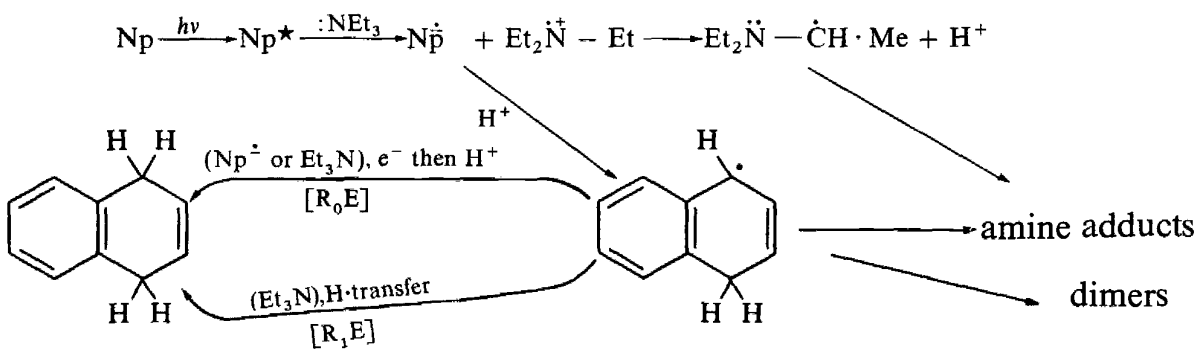

[Np denotes naphthalene]

We now address ourselves to the finer details of the mechanism. First, which state is responsible for the photoreduction? All the evidence points to the reaction proceeding through the lowest singlet excited state. The facts are these:

(i) Benzophenone photosensitization fails to induce the reaction.

(ii) The phosphorescence of naphthalene at $77^{\circ} \mathrm{K}$ in a methanol glass is not quenched by triethylamine. 


\section{THE PHOTOREDUCTION OF AROMATIC SYSTEMS}

This being negative evidence is not entirely satisfactory. More positive is the observation that the fluorescence of naphthalene is efficiently quenched by amines (for $n$ - $\mathrm{Bu}_{3} \mathrm{~N}$ in $\mathrm{MeOH}, k_{\mathrm{q}}=1.9 \times 10^{9} \mathrm{M}^{-1} \mathrm{~s}^{-1} ; k_{\text {diff }} \sim 10^{10} \mathrm{M}^{-1} \mathrm{~s}^{-1}$ ). Furthermore, a plot of the reciprocal of the quantum yield for the disappearance of naphthalene versus the reciprocal of the amine concentration is a straight line and the ratio intercept/gradient gives, within experimental error, the same $k_{\mathrm{q}} \tau$ as is determined from Stern-Volmer plots of fluorescence quenching; see Figures 1 and 2.

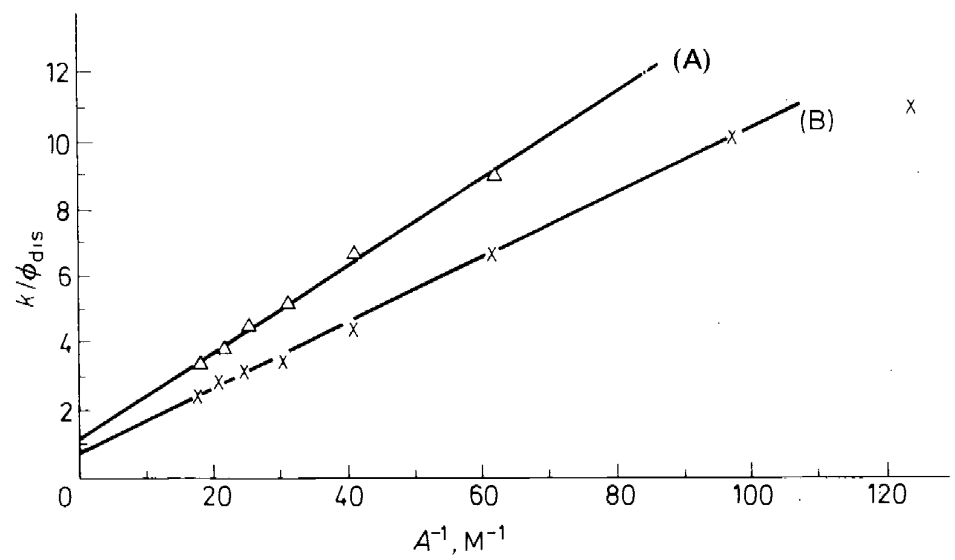

Figure 1. Photochemical reduction of 2-methoxynaphthalene by $\mathrm{Bu}_{3} \mathrm{~N} . \phi_{\mathrm{di}}$ is quantum yield for disappearance of the aromatic; $A$ is concentration of amine. Intercept/gradient $=k_{\mathrm{q}} \tau=9.1$ and $8.4 \mathrm{M}^{-1}$ for curves $A$ and B. $k_{\mathrm{q}} \tau$ from fluorescence quenching $=10.1 \mathrm{M}^{-1}$.

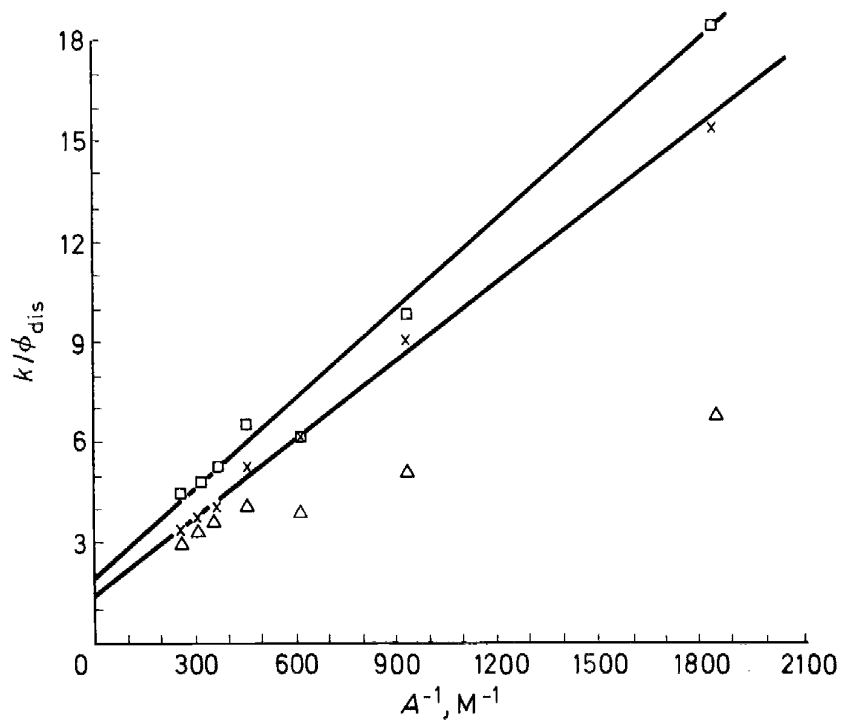

Figure 2. Photochemical reduction of naphthalene by $\mathrm{Bu}_{3} \mathrm{~N}$. $\phi_{\text {dis }}$ is quantum yield for disappearance of naphthalene; $A$ is concentration of amine. $\square$, naphthalene $/ \mathrm{Bu}_{3} \mathrm{~N} ; \Delta$ naphthalene/ $\mathrm{Bu}_{3} \mathrm{~N} /$ piperylene; $\times$ previous curve corrected for loss of naphthalene by photoaddition to piperylene. Intercept/gradient $=k_{\mathrm{q}} \tau=194$ and $218 \mathrm{M}^{-1}$ respectively. $k_{\mathrm{q}} \tau$ from fluorescence quenching $=186 \mathrm{M}^{-1}$. 


\section{J. A. BARLTROP}

This implies that the functional dependence of both fluorescence quenching and photoreduction on the amine concentration is the same. What this means is that both processes involve the same state, though not necessarily the same intermediate. Thus mechanisms such as the following are acceptable:

$$
\begin{aligned}
& \mathrm{Np}^{\star}+\mathrm{Q} \rightleftharpoons\left(\mathrm{Np}^{\star} \ldots \mathrm{Q}\right) \rightarrow \mathrm{Np}_{\mathrm{s}}^{-}+\mathrm{Q}_{\mathrm{s}}^{\ddagger} \rightarrow \text { products } \\
& \text { encounter complex } \\
& \text { Exciplex } \rightarrow h v+\mathrm{Np}+\mathrm{Q}
\end{aligned}
$$

[Np denotes naphthalene; $\mathrm{Q}$ denotes quenching amine]

However, mechanisms involving triplet species can be eliminated because Quenching $\stackrel{\mathrm{Q}}{\llcorner} \mathrm{Np}^{\star} \rightarrow{ }^{3} \mathrm{~Np} \star \stackrel{\mathrm{Q}}{\rightarrow}$ products

both the quantum yield of triplets and their rate of transformation into products will be dependent upon [Q] leading to a non-linear dependence of $\Phi_{\text {products }}^{-1}$ upon [Q] $]^{-1}$. Also piperylene does not noticeably affect $k_{\mathrm{q}} \tau$.

We conclude that the photoreduction occurs via the singlet state of naphthalene by $R_{0} E$ processes.

Whether the photochemistry occurs in an encounter complex or in an exciplex (or both) is not yet clear. However, biphenyl and tertiary aliphatic amines in cyclohexane show both biphenyl and exciplex fluorescence and the lifetimes and emission properties make this a particularly suitable system for investigation by time-resolved fluorimetry. Basically, the system was excited by a nanosecond flash; the fluorescence decay curves were recorded and subjected to a mathematical analysis due to Birks ${ }^{10}$, from which may be extracted the rate constant for exciplex formation $\left(k_{\mathrm{EM}}\right)$ and for reversal of exciplex formation $\left(k_{\mathrm{ME}}\right)$ and the exciplex lifetime $\tau_{\mathrm{E}}$. The details of this work, which will be published elsewhere, do not concern us at this point, but the data obtained from the biphenyl/triethylamine system in cyclohexane, may be of interest:

Table 2. Rate parameters for excited biphenyl/triethylamine system

\begin{tabular}{cccc}
\hline $\begin{array}{c}k_{\text {g }} \\
\left(\begin{array}{c}\text { Stern-Volmer }) \\
\left(\mathrm{M}^{-1} \mathrm{~s}^{-1}\right)\end{array}\right.\end{array}$ & $\begin{array}{c}\tau_{\mathrm{E}} \\
(\mathrm{ns})\end{array}$ & $\begin{array}{c}k_{\mathrm{EM}} \\
\left(\mathrm{M}^{-1} \mathrm{~s}^{-1}\right)\end{array}$ & $\begin{array}{c}k_{\mathrm{ME}} \\
\left(\mathrm{M}^{-1} \mathrm{~s}^{-1}\right)\end{array}$ \\
\hline $8.38 \times 10^{9}$ & 37 & $1.63 \times 10^{9}$ & $2.3 \times 10^{7}$ \\
\hline
\end{tabular}

It can be seen that the rate constant for amine quenching of the fluorescence of biphenyl obtained from a Stern-Volmer plot is about five times as large as the rate constant for exciplex formation. This would seem to suggest that even in a non-polar solvent, where exciplex emission is strong and where exciplexes are clearly present, the dominant quenching mechanism is one which does not involve exciplex formation. This mechanism can scarcely be anything other than electron transfer in an encounter complex. The postulated electron transfer must be reversible (giving reactants in their ground state) since no products are formed when aromatic hydrocarbons are irradiated with aliphatic tertiary amines in cyclohexane. It therefore seems reasonable to conclude provisionally that in polar solvents where exciplex emission is non-existent, quenching and therefore photochemistry is primarily a function of the encounter complex rather than the exciplex. 


\section{PHOTOREDUCTION BY SODIUM BOROHYDRIDE}

We now decided to see whether photoreduction could be induced by hydride transfer agents such as sodium borohydride partly because this reagent might give improved yields, for the formation of adducts seemed unlikely, and partly because if the reduction did indeed proceed by $\mathrm{H}^{-}$ transfer, the products obtained might be expected to differ from those obtained by photoreduction with amines.

The literature revealed that little was known of this area. Most significant was the work of Witkop ${ }^{11}$ who had photoreduced tryptophan with aqueous borohydride and obtained 4,7- (VII) and 2,3-dihydrotryptophans (VIII) as main products:<smiles>NC(Cc1c[nH]c2c1CC=CC2)C(=O)O</smiles>

(VII)<smiles>NC(CC1CNc2ccccc21)C(=O)O</smiles>

(VIII)

He also found ${ }^{12}$ that pyrimidine nucleosides and nucleotides could similarly be reduced, e.g.
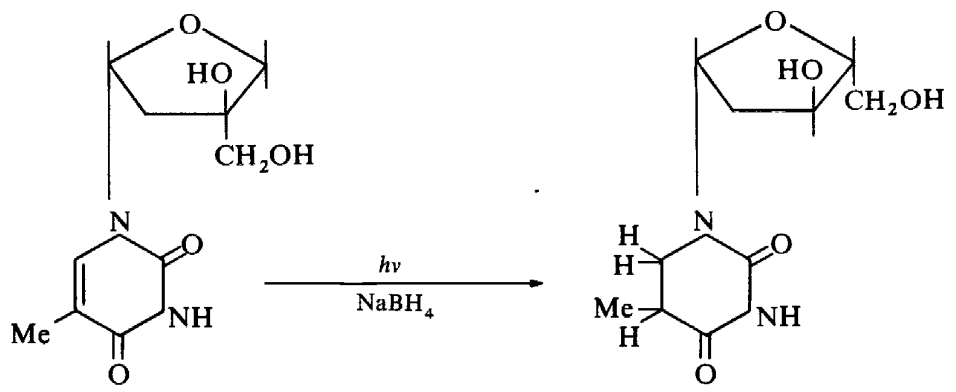

We observed that when 1-cyanonaphthalene was irradiated in $\mathrm{MeCN}$ in the presence of an aqueous alkaline solution of $\mathrm{NaBH}_{4}$ with u.v. light $\lambda>255$ $\mathrm{nm}$, rapid reduction occurred to give the 5,8-dihydronitrile (IX),<smiles>N#Cc1cccc2c1CC=CC2</smiles>

(IX)<smiles>[2H]C1C=CCc2cccc(C#N)c21</smiles>

(X)<smiles>[2H]C1C=CCC2CC1c1c(C#N)cccc12</smiles>

(XI)

which even after two recrystallizations was isolated in 34 per cent yield. Repetition of the reduction using $\mathrm{NaBH}_{4} / \mathrm{D}_{2} \mathrm{O}$ and $\mathrm{NaBD}_{4} / \mathrm{H}_{2} \mathrm{O}$ gave the mono deutero compounds (X) and (XI) respectively.

The positions of the deuteriums were assigned on n.m.r. evidence by comparison with the resonances of $o$ - and $m$-tolunitrile (Table 3). 


\section{J. A. BARLTROP}

Table 3. The n.m.r. spectra of 1-cyanonaphthalene and its deuterated derivatives

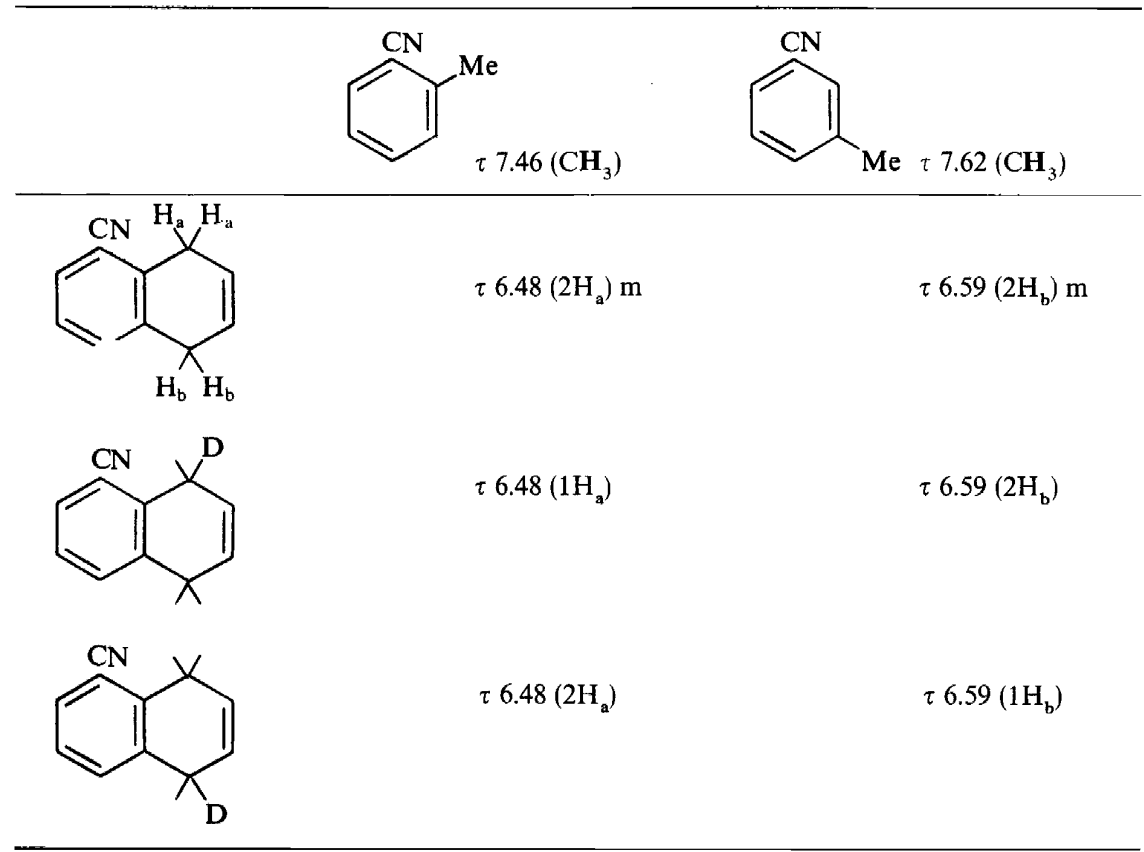

Similarly, 1- and 2-methoxycarbonylnaphthalene gave the compounds (XII) and (XIII) in 44 per cent and 20 per cent yields of isolated material:<smiles>CC(=O)c1cccc2c1CC=CC2</smiles>

(XII)<smiles>COC(=O)c1ccc2c(c1)CC=CC2</smiles>

(XIII)

Logical analysis of these data leads to the conclusion that this reduction proceeds by hydride transfer according to the mechanism $\mathrm{R}_{1} \mathrm{H}^{-}$:

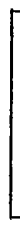<smiles>N#Cc1cccc2ccccc12</smiles><smiles></smiles><smiles>N#Cc1cccc2c1C=CCC2</smiles><smiles>C[OH2+]</smiles><smiles>N#Cc1cccc2c1CC=CC2</smiles>

The arguments are as follows. The only processes that can lead to a dihydro compound involve the transfer of: (i) $\mathrm{H}^{-}$then $\mathrm{H}^{+}$(Type $\mathrm{R}_{1} \mathrm{H}^{-}$), (ii) $\mathrm{H}^{+}$then $\mathrm{H}^{-}$(Type $\mathrm{R}_{1} \mathrm{H}^{+}$), (iii) $2 \mathrm{H}$ (Type $\mathrm{R}_{2}$ ), (iv) initial electron transfer followed by $2 \mathrm{H}^{+}+\mathrm{e}^{-}$or their equivalent (i.e. $\mathrm{H}^{+}+\mathrm{H} \cdot$ ); (Types $\mathrm{R}_{0} \mathrm{E}$ and $\mathrm{R}_{1} \mathrm{E}$ respec- 
tively) or (v) initial $\mathrm{H}^{+}$transfer, then $2 \mathrm{e}^{-}+\mathrm{H}^{+}$or $\mathrm{e}^{-}+\mathrm{H}^{*}$ (Type $\mathrm{R}_{0} \mathrm{H}^{+}$or $\mathrm{R}_{1} \mathrm{H}^{+}$).

$(\alpha)$ We can eliminate initial electron transfer $\left(R_{0} E\right)$ because this would lead to products similar to those obtained from the $\mathrm{R}_{0} \mathrm{E}$ Birch reduction, which tends to introduce hydrogen into the same ring as electron-attracting substituents, or to those products derived from the $\mathrm{R}_{0} \mathrm{E}$ photochemical reduction with amines. As was mentioned earlier (Table 1), photochemical reduction with amines does not occur with the cyano- or carbomethoxy naphthalenes.

$(\beta)$ Initial $\mathrm{H}^{+}$transfer is most improbable because although protons $\left(\mathrm{HClO}_{4}\right)$ quench 1-cyanonaphthalene fluorescence $\left(k_{\mathrm{q}}=1.5 \times 10^{9} \mathrm{M}^{-1} \mathrm{~s}^{-1}\right)$ at a rate comparable with $k_{\mathrm{q}}$ for $\mathrm{NaBH}_{4}\left(k_{\mathrm{q}}=3.3 \times 10^{9} \mathrm{M}^{-1} \mathrm{~s}^{-1}\right)$, their concentration in the alkaline conditions used is so low that they would be incapable of competing effectively with $\mathrm{BH}_{4}^{-}$for the excited species.

$(\gamma) \mathrm{H} \cdot$ transfer (Type $\mathrm{R}_{2}$ ) (mechanism iii) is also unsatisfactory because, if both hydrogens are derived from the same source, be it $\mathrm{NaBH}_{4}$ or $\mathrm{H}_{2} \mathrm{O}$, one cannot explain the incorporation of only one deuterium. Alternatively, if the water and borohydride each provide a hydrogen atom, one cannot explain the difference in labelling patterns obtained from $\mathrm{NaBH}_{4} / \mathrm{D}_{2} \mathrm{O}$ and $\mathrm{NaBD}_{4} / \mathrm{H}_{2} \mathrm{O}$.

$(\delta)$ By elimination, the reduction must take place by initial $\mathrm{H}^{-}$transfer (Type $\mathrm{R}_{1} \mathrm{H}^{-}$).

Mechanistic arguments depending on differences in deuterium labelling obtained from $\mathrm{NaBH}_{4} / \mathrm{D}_{2} \mathrm{O}$ and $\mathrm{NaBD}_{4} / \mathrm{H}_{2} \mathrm{O}$ would clearly be invalidated if there were exchange between the hydrogens of the borohydride and water. This exchange is known to occur ${ }^{13}$, but seemingly it is proton-dependent, possibly occurring via the sequence:

$$
\mathrm{D}^{+}+\mathrm{BH}_{4}^{-} \rightleftharpoons\left[\mathrm{DBH}_{4}\right] \rightleftharpoons \mathrm{DBH}_{3}^{-}+\mathrm{H}^{+}
$$

The rate of exchange is negligibly small under alkaline conditions and such conditions were used in the above irradiations and in the other experiments described below.

On further investigation, it soon became clear that the beautifully simple mechanism outlined for the photoreduction of cyanonaphthalene was not general and that other mechanisms are operative in related systems, for example, indoles.

Indole itself failed to undergo photoreduction when irradiated in the presence of $\mathrm{NaBH}_{4}$. Since the $\mathrm{S}_{1}$ state of indole is known to be acidic, dissociating under the alkaline conditions to excited indole anion, the failure of the photoreduction could be ascribed to the reluctance of the anion to acquire electrons or hydride ions. In agreement with this argument, it was found that indoles, when $N$-methylated, experienced rapid reduction when irradiated with $\mathrm{NaBH}_{4}$. The products, in all cases, were the 2,3-dihydroderivatives; no trace of 4,7-dihydrocompounds, expected from Witkop's work, were to be found. The compounds studied were 1-methyl, 1,2- and 1,3-dimethyl, 1,2,3-trimethyl indole, 1-methyl-2-phenylindole and tetrahydrocarbazole. In all cases, the yield of reduction product was good although sometimes good yields were obtained only at the cost of small conversions.

Again, deuterium experiments were mounted in order to establish the gross features of the mechanism. 


\section{J. A. BARLTROP}

\section{1,2-Dimethylindole}

With $\mathrm{NaBH}_{4} / \mathrm{D}_{2} \mathrm{O}$, the dihydroindole incorporated $0.1 \mathrm{D}$ and with $\mathrm{NaBD}_{4} / \mathrm{H}_{2} \mathrm{O}, 1.8 \mathrm{D}$. These amounts were obtained from n.m.r. integrations. Mass spectrometry, though notoriously unreliable for estimating $\mathrm{H} / \mathrm{D}$ ratios, qualitatively confirmed these results (Figures 3,4 and 5). These facts imply that there are two reduction mechanisms operating simultaneously. In the
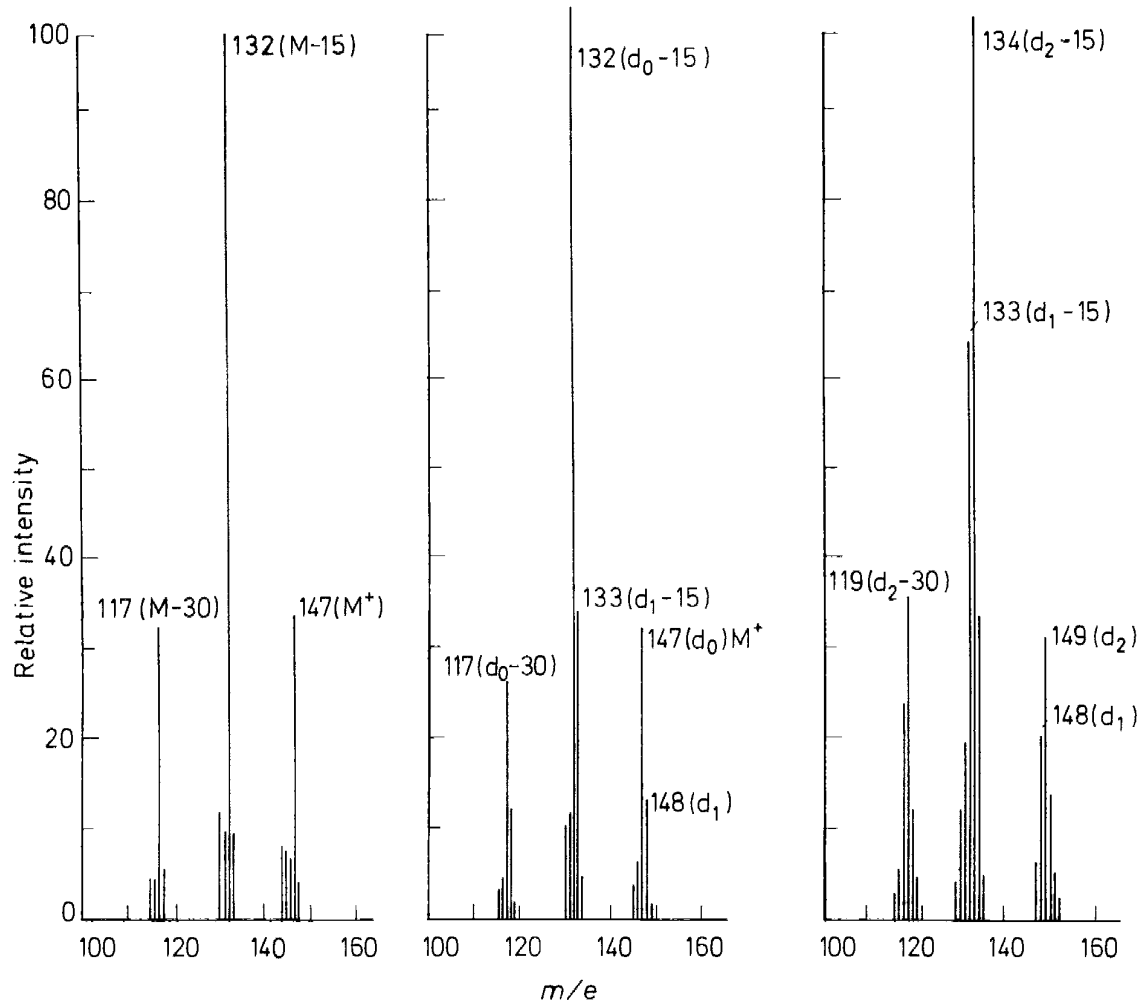

Figure 3. Mass spectrum of 2,3-dihydro-1,2-dimethylindole.

Figure 4. Mass spectrum of dihydroindole obtained by irradiating 1,2-dimethylindole in the presence of $\mathrm{NaBH}_{4} / \mathrm{D}_{2} \mathrm{O}$.

Figure 5. Mass spectrum of dihydroindole obtained by irradiating 1,2-dimethylindole in the presence of $\mathrm{NaBD}_{4} / \mathrm{H}_{2} \mathrm{O}$.

major route $2 \mathrm{D}$ are incorporated from $\mathrm{NaBD}_{4}$ (a Type $\mathrm{R}_{2}$ reaction). This route is a new one, different from any of those discussed previously. If $2 \mathrm{D}$ are derived from $\mathrm{NaBD}_{4}$, then they must be transferred as atoms $\left(\mathrm{D}^{+}\right.$transfer from $\mathrm{BD}_{4}^{-}$is inconceivable and $2 \mathrm{D}^{-}$would not give a neutral product). Whether both deuteriums derive from the same molecule of $\mathrm{NaBD}_{4}$, perhaps by a cyclic concerted mechanism, is not yet clear, but it may be significant that a similar reaction of tetrahydrocarbazole did not give predominantly the expected cis-isomer of hexahydrocarbazole.

The minor pathway is believed to be a Type $\mathrm{R}_{1} \mathrm{H}^{-}$reaction incorporating 
one deuterium from $\mathrm{D}_{2} \mathrm{O}$ and one hydrogen from $\mathrm{BH}_{4}^{-}$because the mass spectrum shows a significant amount of the monodeuterated product. The n.m.r. spectrum of the dihydro compound obtained by reduction with $\mathrm{NaBD}_{4} / \mathrm{H}_{2} \mathrm{O}$ shows the $\mathrm{C}_{(2)}$-methyl signal split into a doublet (Figure 6) indicating that some of the transferred protons are located on $\mathrm{C}_{(2)}$.

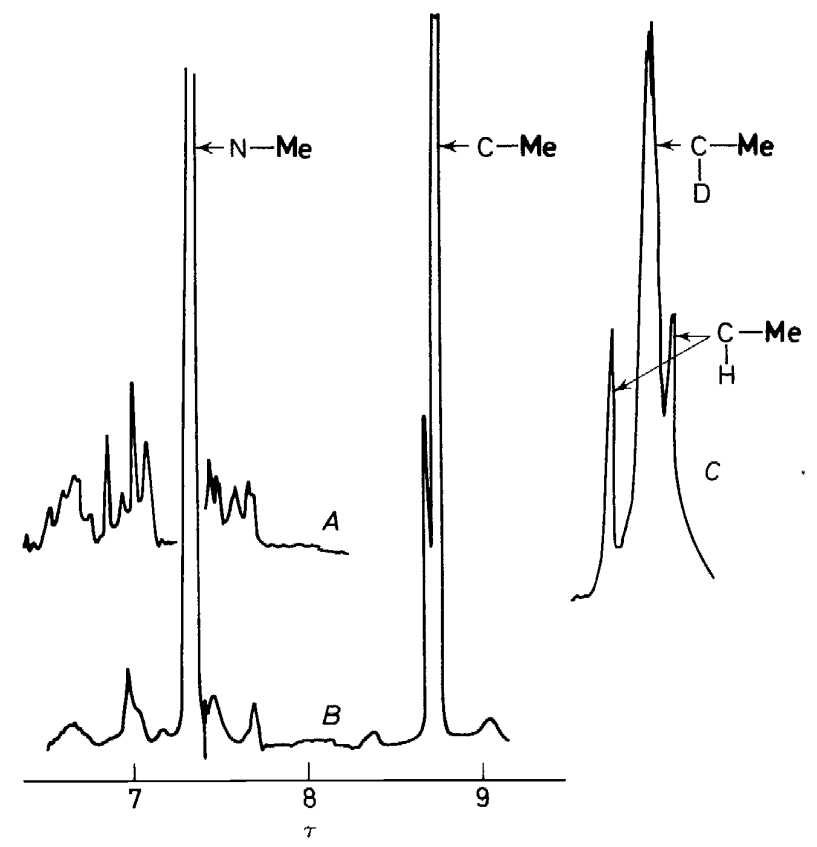

Figure 6. The n.m.r. spectra of reduction products of 1,2-dimethylindole. (A), using $\mathrm{NaBH}_{4} / \mathrm{H}_{2} \mathrm{O}$; signal at $8.7 \tau$ a doublet as with $\mathrm{NaBH}_{4} / \mathrm{D}_{2} \mathrm{O}$. (B) using $\mathrm{NaBD}_{4} / \mathrm{H}_{2} \mathrm{O}$. (C) $8.7 \tau$ signal in curve (B) expanded.

\section{1,3-Dimethylindole}

Here also we seem to have two mechanisms operating simultaneously. The mass spectrum of the dihydro compound obtained by reducing with $\mathrm{NaBH}_{4} / \mathrm{D}_{2} \mathrm{O}$ shows the incorporation mainly of one deuterium and to a lesser extent zero deuterium atoms. No evidence of dideuterated material was found. This exludes a Type $R_{0} E$ mechanism and suggests a mixture of predominant $\mathrm{R}_{1} \mathrm{H}^{-}$and minor $\mathrm{R}_{2}$ processes. The n.m.r. spectra (Figure 7) confirm this view.

Other $N$-methylindoles behave similarly, giving 2,3-dihydro derivatives, but the results of deuterium studies are not yet available.

\section{BENZENE DERIVATIVES}

It is found that $\mathrm{NaBH}_{4}$ reduces excited carboxylic esters of the benzene series, but the process seems to be more complicated than that encountered with the naphthoic esters. As yet only a few of the products have been isolated 

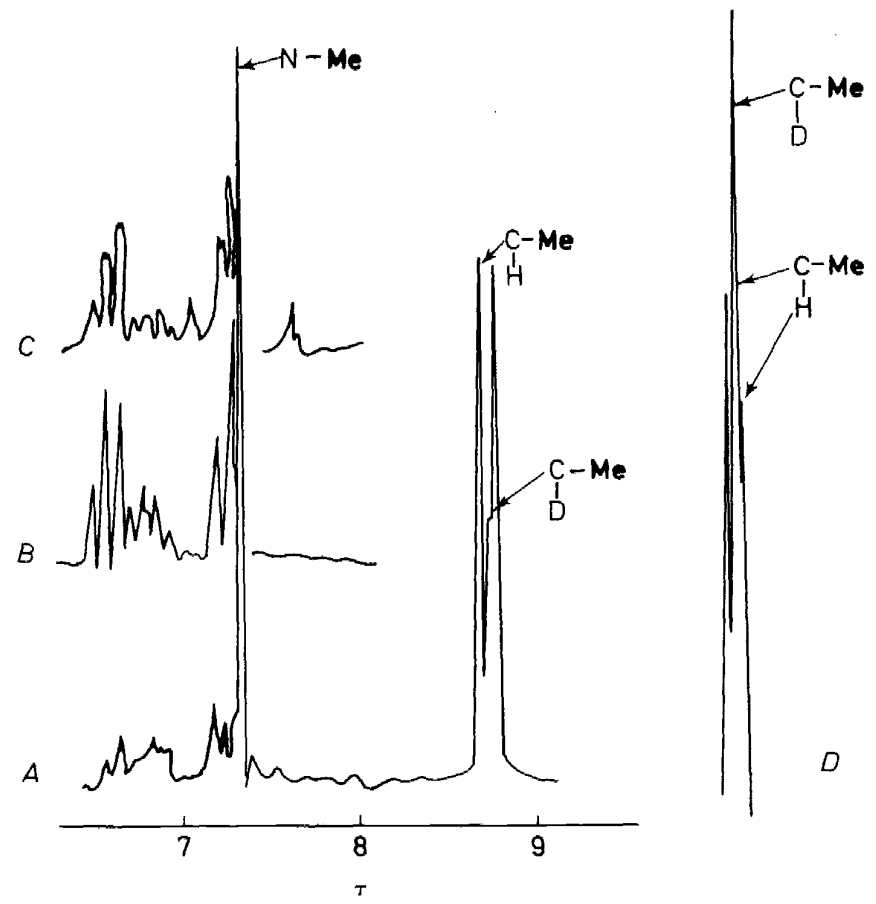

Figure 7. The n.m.r. spectra of reduction products of 1,3-dimethylindole. (A) using $\mathrm{NaBD}_{4} / \mathrm{H}_{2} \mathrm{O}$. (B) using $\mathrm{NaBH}_{4} / \mathrm{H}_{2} \mathrm{O}$; doublet at $8.7 \tau$. (C) using $\mathrm{NaBH}_{4} / \mathrm{D}_{2} \mathrm{O}$. (D) $8.7 \tau$ signal in (C),

and little is known of the mechanistic pathways, but our preliminary data are exhibited in Table 5.

Table 5. Photoreduction by $\mathrm{BH}_{4}^{-}$of esters of the benzene series

Starting materials




\section{CONCLUSIONS}

Our investigations into photochemical reductions are as yet only at a preliminary stage. Nertheless we seem to have identified three reaction types; $R_{2}, R_{1} \mathbf{H}^{-}$and $R_{0} \mathbf{A}$ large number of questions remain unanswered -are other photochemical reduction mechanisms accessible, e.g. $\mathrm{R}_{1} \mathrm{H}^{+}$; what determines which mechanism operates in a particular case; how can one optimize the yields and so on? We hope that answers to some of these questions will emerge during the course of future investigations.

\section{ACKNOWLEDGEMENTS}

It is a pleasure to pay tribute to my colleagues, Keith Dawes, Roger Owers, Iain Denniss and George Senior and David Bradbury who have conducted the experiments so skilfully, and contributed stimulus and valuable criticism to the development of the research. Financial support by the Science Research Council and by Kodak Ltd, is gratefully acknowledged.

\section{REFERENCES}

1 S. G. Cohen and R. J. Baumgarten. J. Amer. Chem. Soc. 89, 3471 (1967) and refs therein.

${ }^{2}$ H. Knibbe, D. Rehm and A. Weller. Ber. Bunsenges. Phys. Chem. 72, 257 (1968).

${ }^{3}$ D. Rehm and A. Weller, Israel J. Chem. 8, 259 (1970).

D. Rehm and A. Weller, Ber. Bunsenges. Phys. Chem. 73, 834 (1969).

${ }^{4}$ M. G. Kuzmin and L. N. Guseva, Chem. Phys, Letters, 3, 71 (1969).

5 J. A. Barltrop and R. J. Owers. Chem. Commun. 1462 (1970).

6 A. J. Birch. Quart. Rev. 4, 69 (1950).

${ }^{7}$ Shui Pong Van. Ph.D. Thesis, California Institute of Technology (1970).

8 C. Pac and H. Sakurai. Tetrahedron Letters, 3829 (1969).

R. S. Davidson, Chem. Commun. 1450 (1969).

9 A. Nakajima. Bull. Chem. Soc. Japan, 42, 3409 (1969).

10 J. B. Birks, D. J. Dyson and I. H. Munroe. Proc. Roy. Soc. A, 275, 575 (1963).

11 O. Yonemitsu, P. Cerutti and B. Witkop. J. Amer. Chem. Soc. 88, 3941 (1966).

12 G. Ballé, P. Cerutti and B. Witkop. J. Amer. Chem. Soc. 88, 3946 (1966).

13 R. H. Cornforth. Tetrahedron, 26, 4635 (1970). 